\title{
Evaluasi alokasi Tempat Pembuangan Sampah Sementara (TPSS) di Kecamatan Denpasar Selatan dengan aplikasi GIS
}

\author{
Siti Ainur Rohmah¹, I Gst. A. Ayu Rai Asmiwyati ${ }^{1 \star}$, Anak Agung Gede Sugianthara ${ }^{1}$ \\ 1. Program Studi Arsitektur Pertamanan, Fakultas Pertanian, Universitas Udayana, Jl. PB Sudirman \\ Denpasar, Indonesia \\ *E-mail : asmiwyati@unud.ac.id
}

\begin{abstract}
Abtract
Evaluation of Allocation Temporary Landfill in Denpasar Selatan Subdistrict with Geographic Information System Applications. One of sub-district in Denpasar that still faces garbage problems is South Denpasar which is due to its high population. The population of South Denpasar is 286,060 people. Based on the data obtained, each individual can dispose up to $0.004 \mathrm{~m}^{3}$ garbage each day. This the volume of waste in the population of South Denpasar Sub-district each day is $1,144.24 \mathrm{~m}^{3}$. However, the amount of waste has not been accommodated well within the number of existing landfills. This study aim is to determine the location of landfill in South Denpasar District. The variables used to determine the suitability of the landfill location are the road to the location, the distance of landfill to the river, land use, land availability and regional boundaries. The number of was determine by points in South Denpasar, amount of waste each day, number of existing population, perceptions and preferences of the people of South Denpasar. The analysis of landfill location was run by using a geographic information system (GIS). This research uses survey methods and data collection with an active approach of activities carried out on the site. The results of the analysis showed that there were 11 landfills recommendations. The location of these recommendations is in the immediate area of reach, which is within $1-2 \mathrm{~km}$.
\end{abstract}

Keyword : population, South Denpasar, trash, temporary rubbish shelter

1. Pendahuluan

Sampah merupakan masalah yang banyak dihadapi oleh negara-negara berkembang seperti Indonesia. Total keseluruhan sampah tersebut berasal dari sampah permukiman seperti perumahan, apartemen dan sampah non permukiman seperti industri, rumah sakit dan institusi. Manajemen pengelolaan sampah perkotaan di Indonesia masih menghadapi banyak kendala terutama dalam hal keberadaan TPS dan TPA yang belum mencukupi kebutuhan masyarakatnya. Berbagai cara telah dilakukan oleh pemerintah dalam pengelolaan sampah, akan tetapi laju kenaikan volume sampah membuat pemerintah kewalahan. Secara nasional diperkirakan hanya 60-70\% dari total sampah perkotaan yang dapat diangkut ke TPA oleh instansi pemerintah yang berwenang (Damanhuri, 2008).

Denpasar Selatan merupakan salah satu kecamatan yang masih mengalami permasalahan tempat pembuangan sampah sementara (TPSS) akibat dari jumlah penduduk yang tinggi. Menurut Kepala Bidang Pengelolaan Sampah dan Limbah B3 Kota Denpasar, jumlah TPSS di Denpasar Selatan ada lima titik TPSS yang dikelola oleh pihak DLHK dan tiga TPSS dikelola oleh desa. Penduduk Kecamatan Denpasar Selatan yang berjumlah 286.060 jiwa (DLHK, 2018). Berdasarkan data yang didapatkan setiap harinya volume sampah penduduk Kecamatan Denpasar Selatan sebanyak 1.144,24 $\mathrm{m}^{3}$, maka setiap individu membuang 0,004 $\mathrm{m}^{3}$ sampah setiap harinya (DLHK, 2016). Jumlah sampah tersebut belum memadai dengan jumlah tempat pembuangan sampah yang ada. Dengan permasalahan tersebut penelitian ini bertujuan mengevaluasi TPSS eksisting dan menentukan lokasi TPSS rekomendasi di Kecamatan Denpasar Selatan menggunakan Sistem Informasi Geografis. Variabel yang digunakan untuk menentukan kesesuaian lokasi TPSS yaitu jalan menuju lokasi, jarak TPSS terhadap sungai, penggunaan lahan, ketersediaan lahan dan batas wilayah. Jumlah titik TPSS ditentukan oleh jumlah sampah setiap hari, jumlah penduduk yang ada, serta didukung persepsi dan preferensi masyarakat Denpasar Selatan. 


\section{Metode Penelitian}

Penelitian evaluasi alokasi tempat pembuangan sampah sementara dilaksanakan selama lima bulan yaitu mulai Mei sampai dengan September 2018 di Kecamatan Denpasar Selatan. Kecamatan Denpasar Selatan terdiri dari empat desa dan enam kelurahan yaitu: Desa Sidakarya, Desa Pemogan, Desa Sanur Kaja, Desa Sanur Kauh, Kelurahan Serangan, Kelurahan Pedungan, Kelurahan Sesetan, Kelurahan Panjer, Kelurahan Renon, dan Kelurahan Sanur. Penelitian ini menggunakan metode survei dengan tiga tahapan yaitu: Tahap I. Persiapan dan inventarisasi data, Tahap II. Analisis deskriptif berupa sistem pengelolaan sampah serta aturan peletakkan TPSS dan analisis spasial menggunakan GIS sebagai pemetaan lahan berpotensi sebagai TPSS, Tahap III. Sintesis berupa lokasi TPSS yang direkomendasikan.

\section{Hasil dan Pembahasan}

\subsection{Aspek Biofisik}

Secara geografis Kecamatan Denpasar Selatan berada pada koordinat $08^{\circ} 040^{\prime} 00^{\prime \prime}-08^{\circ} 044^{\prime} 49^{\prime \prime}$ LS dan $115^{\circ} 011^{\prime} 23^{\prime \prime}-115^{\circ} 015^{\prime} 54$ BT. Luas wilayah Kecamatan Denpasar Selatan yaitu $49,99 \mathrm{~km}^{2}$ atau 4.999 hektar. Batas-batas wilayah Denpasar Selatan yaitu, di sebelah utara ada Kecamatan Denpasar Timur, di sebelah timur berbatasan dengan Selat Badung, di sebelah selatan berbatasan dengan Selat Badung dan di sebelah barat berbatasan dengan Kecamatan Denpasar Barat dan wilayah Kabupaten Badung (BPS, 2017).

Terdapat lima jenis jalan yang ada di Kecamatan Denpasar Selatan yaitu jalan bebas hambatan, jalan arteri primer, jalan kolektor primer Nasional (K-1), jalan arteri sekunder, jalan kolektor sekunder, dan jalan lingkungan. Jalan arteri primer yaitu jalan by pass Ngurah Rai yang menghubungkan mulai dari wilayah Pemogan, Pedungan, Sesetan, Serangan, Sanur Kauh, Kelurahan Sanur dan Sanur Kaja. Jalan Kolektor Primer Nasional (K-1) yaitu yang berada di jalan raya Sesetan yang menghubungkan ke pusat kota. Jalan arteri sekunder yaitu jalan Pulau Moyo yang menghubungkan wilayah Pedungan dengan Pemogan. Jalan kolektor sekunder yaitu jalan Sidakarya, jalan Mertasari, jalan Tukad Pakerisan dan Waturengggong yang menghubungkan daerah Sidakarya, Panjer dan Renon (Gambar 1).

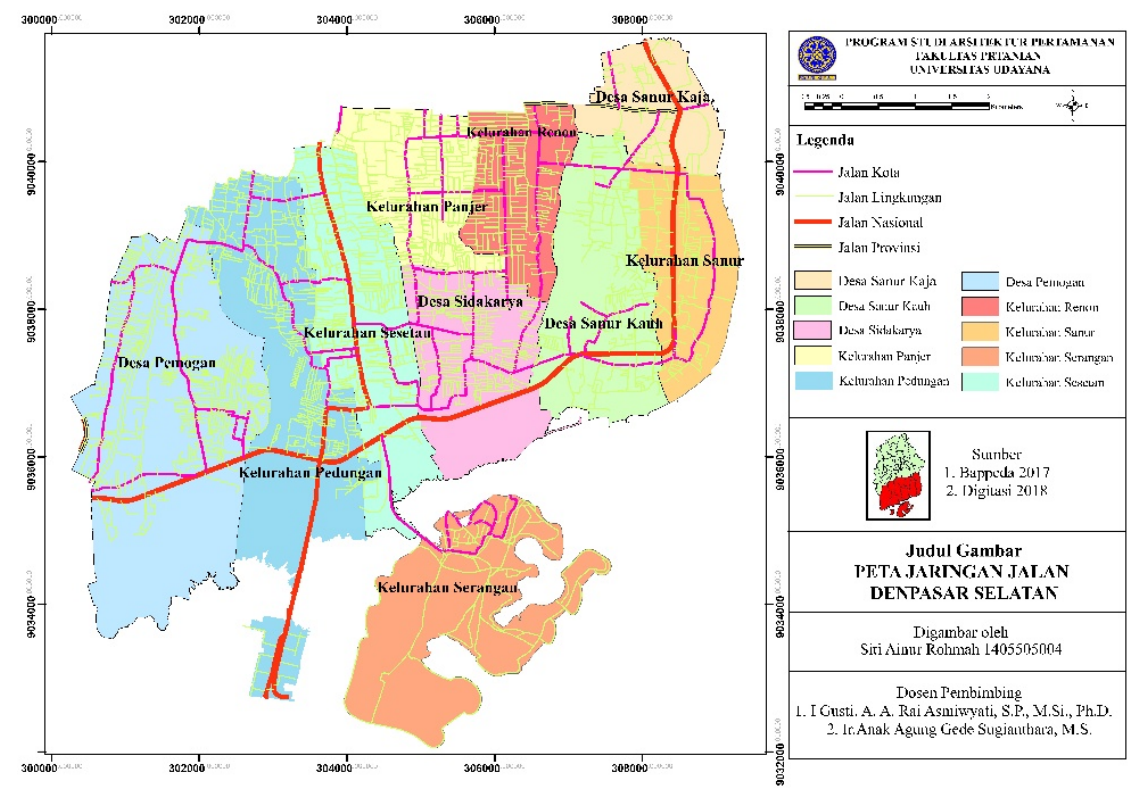

Gambar 1. Peta Jaringan Jalan

Fasilitas TPSS yang berada di Kecamatan Denpasar Selatan berjumlah lima yang dikelola oleh pemerintah dan tiga lokasi yang dikelola sendiri oleh desa. Lokasi TPSS eksisting Denpasar Selatan yaitu di jalan Pulau Kawe Kelurahan Pedungan, jalan Citarum di Kelurahan Panjer, jalan Mertasari di Desa Sidakarya, jalan Gurita lingkungan banjar Pegok Kelurahan Sesetan, jalan Tukad Punggawa Kelurahan Serangan, jalan Tukad Nyali Sanur Kaja, Gang Zamrud jalan Batur Sari Sanur Kauh dan jalan Danau Tempe Sanur Kauh TPS 3R (DLHK, 2016) (Gambar 2). Berdasarkan data yang diambil di lapangan menunjukkan kondisi TPSS eksisting yang ada di Denpasar Selatan. Sebagian TPSS dalam kondisi bagus serta masih layak dan ada tiga 
lokasi yang dalam kondisi kurang layak atau dapat dikatakan masih mengganggu lingkungan sekitar. Berikut merupakan kondisi dan analisis dari TPSS eksisting Denpasar Selatan (Tabel 1).
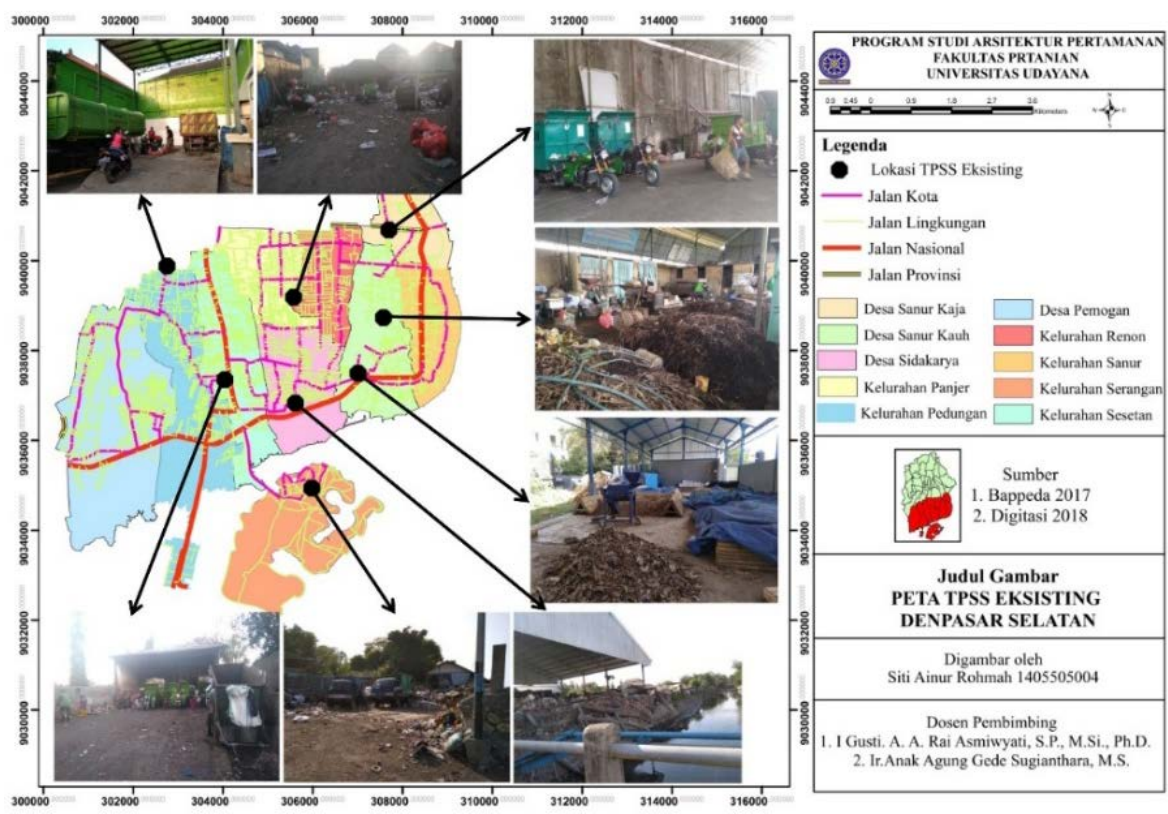

Gambar 2. Peta Lokasi dan Kondisi TPSS Eksisting

Tabel 1. Kondisi dan Analisis TPSS Eksisting

\begin{tabular}{|c|c|}
\hline $\begin{array}{c}\text { Lokasi } \\
\text { TPSS Eksisting }\end{array}$ & Kondisi \\
\hline Jalan Pulau Kawe Pedungan & $\begin{array}{l}\text { Sudah bagus } \\
>\text { Area cukup untuk parkir truk dan alat operasional } \\
>\text { Model TPSS dengan sistem underground }\end{array}$ \\
\hline Jalan Gurita Sesetan & $\begin{array}{l}>\text { Masih bagus } \\
>\text { Area cukup untuk parkir truk dan alat operasional } \\
>\text { Model TPSS bangunan permanen }\end{array}$ \\
\hline Jalan Citarum Panjer & $\begin{array}{l}>\text { Kurang bagus } \\
>\text { Tembok pembatas dengan rumah warga tidak ada } \\
>\text { Lokasi parkir truk dan moci tidak jelas }\end{array}$ \\
\hline $\begin{array}{l}\text { Jalan Tukad Punggawa } \\
\text { Serangan }\end{array}$ & $\begin{array}{l}>\text { Kurang bagus } \\
>\text { tembok pembatas terlihat kurang memadai } \\
>\text { Sampah terlihat tercecer sampai pintu masuk } \\
>\text { Kurang terawat }\end{array}$ \\
\hline Jalan Mertasari Sidakarya & $\begin{array}{l}>\text { Kondisi Rusak } \\
>\text { Tembok ambrol kearah sungai } \\
>\text { Mempunyai area cukup untuk parkir truk dan alat } \\
\text { operasional lainnya } \\
>\text { Mempunyai pengolahan khusus untuk sampah organik }\end{array}$ \\
\hline Jalan Tukad Nyali Sanur Kaja & $\begin{array}{l}>\text { Bagus } \\
>\text { Area cukup untuk menampung } \mathrm{MOCl} \text { yang ada } \\
\text { Truk dan alat operasional dapat mengakses jalur } \\
\text { dengan mudah } \\
>\begin{array}{l}\text { Jalur masuk ke area memadai sehingga tidak } \\
\text { mengganggu jalan utama }\end{array}\end{array}$ \\
\hline Jalan Batur Sari Sanur Kauh & $\begin{array}{l}\text { Masih layak } \\
\text { Kurang tertata } \\
\text { Bangunan masih semi permanen } \\
\text { Tanah masih meminjam milik warga } \\
\text { Ada fasilitas untuk memilah sampah organik dan } \\
\text { anorganik } \\
\begin{array}{l}\text { Ada alat untuk memproses sampah organik untuk } \\
\text { dijadikan pupuk }\end{array}\end{array}$ \\
\hline
\end{tabular}

TPSS underground merupakan TPSS yang sesuai dengan kebutuhan kota yang padat penduduk sehingga TPSS tersebut tidak memberikan kerugian masyarakat sekitar akibat pencemaran.

Keberadaannya masih dekat dengan sungai dan masyarakat masih banyak yang terganggu oleh TPSS tersebut karena banyak yang menggunakan fasilitas lapangan Arga Coka Pegok yang berada di sampingnya.

Penempatannya sudah sesuai, karena dekat dengan sumber sampah yaitu permukiman, namun masih dekat dengan sungai.

Area TPSS dapat diakses truk dan alat operasional lainnya.

TPSS Serangan fasilitas yang terlihat kurang terurusdan tidak selayak TPSS yang lainnya.

Penempatannya masih kurang tepat karena berada dekat sungai

Lokasi penempatan kurang tepat karena berada dekat sungai. Pengangkutan tidak bisa bersih, selalu ada sisa sampah setelah diangkut ke TPA sehingga masih menimbulkan bau

TPSS Sanur Kaja lokasi penempatan kurang tepat karena dekat sungai

Penempatannya dekat dengan sungai 


\begin{tabular}{|c|c|c|c|}
\hline & $\begin{array}{c}\text { Lokasi } \\
\text { TPSS Eksisting }\end{array}$ & Kondisi & Analisis \\
\hline $\begin{array}{l}\text { Jalan } \\
\text { Kauh }\end{array}$ & Danau Tempe Sanur & $\begin{array}{l}\text { Bagus } \\
\text { Koordinasi desa dengan masyarakat bagus } \\
\text { Ada pengelola pemisahan sampah organik anorganik } \\
\text { Ada alat untuk memproses sampah organic untuk } \\
\text { pupuk }\end{array}$ & $\begin{array}{l}\text { TPSS 3R Sanur Kauh area yang digunakan luas } \\
\text { sehingga tidak mengganggu lingkungan maupun jalan } \\
\text { disekitar. } \\
\text { Lokasi masih dekat dengan sungai. } \\
\text { Pengelolaan sudah bagus. }\end{array}$ \\
\hline
\end{tabular}

\section{$3.2 \quad$ Aspek Sosial}

\subsubsection{Jumlah Penduduk}

Berdasarkan data yang diperoleh dari Badan Pusat Statistika Kota Denpasar tahun 2017 Kecamatan Denpasar Selatan memiliki jumlah penduduk terbesar diantara kecamatan yang lainnya yaitu 286.060 jiwa, dengan jumlah kepala keluarga 36.722 yang terdiri dari 146.220 jiwa peduduk laki-laki $(51,12 \%)$ dan 139.840 jiwa (48,88\%) penduduk perempuan. Berdasarkan data jumlah penduduk yang diperoleh, maka Kecamatan Denpasar Selatan memiliki jumlah kepadatan penduduk 5.722 jiwa/km² (BPS, 2017). Jumlah penduduk merupakan faktor penentu jumlah TPSS yang akan direncanakan, karena semakin banyak jumlah penduduk semakin banyak pula jumlah sampah yang ditimbulkan. Untuk menghasilkan titik TPSS yang direncanakan yaitu dihitung dari hasil jumlah sampah tertampung dibagi dengan rata-rata ukuran TPSS eksisting menghasilkan 11 lokasi TPSS rekomendasi.

\subsubsection{Persepsi dan Preferensi Masyarakat}

Tujuan dari persepsi dan preferensi adalah untuk mengetahui informasi dari pengguna TPSS dan untuk mengetahui karakter serta harapan masyarakat terhadap TPSS yang sudah ada. Untuk mengetahui persepsi dan preferensi masyarakat dalam penelitian ini dilakukan penyebaran kuesioner dan wawancara.

Pertanyaan-pertanyaan kuesioner diisi oleh 80 responden pengguna TPSS di wilayah Kecamatan Denpasar Selatan. Panduan ukuran sampel yang diambil ditentukan dengan cara mengalikan jumlah variabel dengan lima (lima kali jumlah variabel). Dengan demikian, jumlah sampel penelitian ini adalah 80 sampel yang diperoleh dari 16 jumlah variabel dikalikan lima $(16 \times 5=80)($ Sekaran, 2003). Berikut merupakan hasil dari kuesioner serta analisis dan sintesis untuk mengetahui penggunaan dan keberadaan TPSS di sekitar masyarakat Denpasar Selatan dari segi aspek sosial (Tabel 2 dan Tabel 3).

Tabel 2. Analisis Persepsi Masyarakat terhadap TPSS Eksisting

\begin{tabular}{|c|c|c|c|}
\hline No & Persepsi Masyarakat & Analisis & Sintesis \\
\hline 1. & Keberadaan TPSS & $\begin{array}{l}\text { Masyarakat Denpasar Selatan } \\
\text { dominan mengetahui keberadaan } \\
\text { TPSS yang ada dilingkungannya. }\end{array}$ & $\begin{array}{l}\text { Masyarakat Denpasar Selatan dominan mengetahui } \\
\text { lokasi TPSS yang ada di daerahnya. Masyarakat yang } \\
\text { tidak mengetahui keberadaan TPSS merupakan } \\
\text { masyarakat pendatang. }\end{array}$ \\
\hline 2. & Menggunakan TPSS & $\begin{array}{l}\text { Masyarakat Denpasar Selatan } \\
\text { cenderung menggunakan fasilitas } \\
\text { TPSS }\end{array}$ & $\begin{array}{l}\text { Masyarakat Denpasar Selatan cenderung ikut } \\
\text { menggunakan TPSS baik secara langsung maupun tidak } \\
\text { langsung (diambil oleh petugas). Beberapa warga yang } \\
\text { tidak ikut menggunakan TPSS mengaku membakarnya } \\
\text { dan ada yang dibuang di lahan kosong secara } \\
\text { sembarangan. }\end{array}$ \\
\hline 3. & $\begin{array}{l}\text { TPSS yang mengganggu } \\
\text { lingkungan }\end{array}$ & $\begin{array}{l}\text { Menurut responden keberadaan } \\
\text { TPSS masih banyak yang } \\
\text { mengganggu lingkungan. }\end{array}$ & $\begin{array}{l}\text { Masyarakat yang tempat tinggalnya dekat dengan lokasi } \\
\text { TPSS masih merasa terganggu dengan bau dan } \\
\text { pencemaran lingkungan yang ditimbulkan. } \\
\text { Menggunakan sistem yang modern merupakan salah satu } \\
\text { kebutuhan ditengah masyarakat kota, agar polusi yang } \\
\text { ditimbulkan sampah tidak dapat mengganggu lingkungan } \\
\text { sekitar. }\end{array}$ \\
\hline 4. & $\begin{array}{l}\text { TPSS yang mengganggu } \\
\text { lalu lintas }\end{array}$ & $\begin{array}{l}\text { Menurut responden TPSS yang } \\
\text { ada sudah cenderung tidak } \\
\text { mengganggu lalu lintas. }\end{array}$ & $\begin{array}{l}\text { Masyarakat yang sering melewati lokasi TPSS terkadang } \\
\text { merasa terganggu karena truk sampah yang } \\
\text { menyebabkan tersendatnya lalu lintas. }\end{array}$ \\
\hline 5. & $\begin{array}{l}\text { Intensitas pembuangan } \\
\text { sampah warga }\end{array}$ & $\begin{array}{l}\text { Masyarakat Denpasar Selatan lebih } \\
\text { dominan memilih menggunakan } \\
\text { jasa pengambilan sampah. }\end{array}$ & $\begin{array}{l}\text { Berdasarkan hasil penelitian masyarakat Denpasar } \\
\text { memilih menggunakan jasa pengambilan sampah yang } \\
\text { dilakukan oleh pihak swakelola menggunakan } \mathrm{MOCl} \\
\text { (Motor Cikar) dan dikenakan biaya operasional } \\
\text { Rp.30.000,00 per bulan per kepala keluarga. }\end{array}$ \\
\hline 6. & $\begin{array}{l}\text { Penempatan TPSS yang } \\
\text { sudah tepat }\end{array}$ & $\begin{array}{lrr}\text { Masyarakat } & \text { Denpasar } & \text { Selatan } \\
\text { dominan menganggap } & \text { TPSS } \\
\text { eksisting belum } & \text { tepat } \\
\text { keberadaannya. } & \end{array}$ & $\begin{array}{l}\text { Masyarakat yang tempat tinggalnya jauh dari TPSS } \\
\text { sudah merasa tepat dengan keberadaan TPSS, namun } \\
\text { yang sering melintas dan tempat tinggalnya dekat } \\
\text { dengan TPSS masih merasa terganggu. }\end{array}$ \\
\hline
\end{tabular}




\begin{tabular}{|c|c|c|c|}
\hline No & Persepsi Masyarakat & Analisis & Sintesis \\
\hline \multirow[t]{2}{*}{7.} & TPSS yang mengganggu & Responden menganggap & Masyarakat menganggap TPSS eksisting masih \\
\hline & estetika wajah kota & $\begin{array}{l}\text { keberadaan TPSS masih } \\
\text { mengganggu estetika wajah kota. }\end{array}$ & $\begin{array}{l}\text { mengganggu estetika wajah kota karena masih banyak } \\
\text { sampah yang dibuang secara sembarangan. }\end{array}$ \\
\hline 8. & $\begin{array}{l}\text { TPSS yang sesuai dengan } \\
\text { Kebutuhan }\end{array}$ & $\begin{array}{l}\text { Masyarakat Denpasar Selatan } \\
\text { menganggap TPSS eksisting } \\
\text { belum mencukupi kebutuhan. }\end{array}$ & $\begin{array}{l}\text { TPSS eksisting belum dapat mencukupi kebutuhan } \\
\text { masyarakat. Aturan mengenai pembuangan sampah } \\
\text { setiap daerah belum ada penertiban. Jumlah TPSS } \\
\text { eksisting belum sesuai dengan jumlah penduduk. }\end{array}$ \\
\hline 9. & $\begin{array}{l}\text { Harapan Masyarakat } \\
\text { terhadap TPSS }\end{array}$ & $\begin{array}{l}\text { TPSS yang ada dapat memberikan } \\
\text { solusi dari pada pencemaran } \\
\text { lingkungan }\end{array}$ & $\begin{array}{l}\text { Harapan responden terhadap TPSS yaitu polusi sampah } \\
\text { dapat teratasi, pengelolaan semakin bagus, tidak ada lagi } \\
\text { sampah berserakan atau tercecer dan pembuangan } \\
\text { sampah secara sembarangan. TPSS diperbanyak } \\
\text { dengan sistem yang lebih modern. }\end{array}$ \\
\hline
\end{tabular}

Tabel 3. Analisis Preferensi Masyarakat terhadap TPSS Eksisting

\begin{tabular}{|c|c|c|c|}
\hline No & Preferensi Masyarakat & Analisis & Sintesis \\
\hline \multirow[t]{2}{*}{1.} & Respon Masyarakat & Masyarakat lebih memi & TPSS yang ideal yaitu TPSS yang sesuai dengan jumlah \\
\hline & $\begin{array}{l}\text { Terhadap TPSS yang } \\
\text { melampaui batas }\end{array}$ & $\begin{array}{l}\text { sampah ditempat lain ketika TPSS } \\
\text { yang tersedia melampaui batas. }\end{array}$ & $\begin{array}{l}\text { penduduk, untuk menghindari permasalahan } \\
\text { pembuangan sampah secara sembarangan dan } \\
\text { pembakaran sampah. Setiap desa ataupun kelurahan } \\
\text { diharuskan mempunyai TPSS sendiri. }\end{array}$ \\
\hline \multirow[t]{2}{*}{2.} & $\begin{array}{lr}\text { Respon } & \text { Masyarakat } \\
\text { ketika } & \text { TPSS }\end{array}$ & $\begin{array}{l}\text { Responden lebih dominan melapor ke } \\
\text { petugas yang beriaga ketika TPSS }\end{array}$ & $\begin{array}{l}\text { TPSS yang tersedia harus memiliki tempat parkir khusus } \\
\text { agar tidak mengqangqu lalu lintas maupun lingkungan }\end{array}$ \\
\hline & $\begin{array}{l}\text { Mengganggu Lingkungan } \\
\text { atau Fungsi Jalan }\end{array}$ & $\begin{array}{l}\text { yang ada mengganggu lingkungan } \\
\text { ataupun fungsi jalan }\end{array}$ & sekitar. \\
\hline \multirow[t]{2}{*}{3.} & Lokasi TPSS yang Tepat & $\begin{array}{l}\text { Responden dominan berpendapat } \\
\text { bahwa TPSS yang tepat tidak terletak } \\
\text { area permukiman. }\end{array}$ & $\begin{array}{l}\text { TPSS yang ramah terhadap lingkungan. Ketersediaan } \\
\text { lahan yang sesuai dengan kebutuhan masyarakat. }\end{array}$ \\
\hline & $\begin{array}{l}\text { Persetujuan Masyarakat } \\
\text { jika disekitar Rumahnya } \\
\text { disediakan TPSS }\end{array}$ & $\begin{array}{l}\text { Sebagian besar masyarakat tidak } \\
\text { setuju jika di sekitar rumahnya } \\
\text { disediakan TPSS dan sebagian } \\
\text { setuju. }\end{array}$ & $\begin{array}{l}\text { Polusi udara dan pencemaran lingkungan yang } \\
\text { ditimbulkan sampah. } \\
\text { Alternatif pengelolaan yang baik dan menggunakan } \\
\text { sistem yang modern seperti underground. }\end{array}$ \\
\hline 4. & $\begin{array}{lr}\text { Respon } & \text { masyarakat } \\
\text { ketika } & \text { dihimbau } \\
\text { Pemerintah } & \end{array}$ & $\begin{array}{l}\text { Masyarakat lebih dominan setuju } \\
\text { ketika dihimbau pemerintah untuk } \\
\text { ketersediaan lahan sebagai TPSS di } \\
\text { sekitar lingkungannya, namun } \\
\text { dengan syarat. }\end{array}$ & $\begin{array}{l}\text { Tidak mengganggu lingkungan mulai dari pencemaran } \\
\text { udara, pencemaran limbah dan tidak mengganggu lalu } \\
\text { lintas. Menggunakan sistem pengelolaan yang bagus } \\
\text { serta alat yang modern seperti underground. }\end{array}$ \\
\hline 5. & $\begin{array}{l}\text { Respon Masyarakat } \\
\text { terhadap TPSS Modern } \\
\text { atau Underground. }\end{array}$ & $\begin{array}{l}\text { Masyarakat dominan setuju dengan } \\
\text { sistem modern seperti TPSS } \\
\text { underground di Jalan Pulau Kawe. }\end{array}$ & $\begin{array}{l}\text { Masyarakat Denpasar Selatan cenderung setuju } \\
\text { dengan sistem underground seperti yang ada di Jalan } \\
\text { Pulau Kawe. } \\
\text { Manfaat underground diantaranya tidak menyebabkan } \\
\text { pencemaran lingkungan akibat limbah sampah, tidak } \\
\text { menyebabkan polusi udara, karena langsung masuk di } \\
\text { Underground jadi sampah tidak menimbulkan bau. } \\
\text { Alarm saat sampah sudah penuh. } \\
\text { Kekurangan tidak ada pemisahan sampah organik dan } \\
\text { anorganik. }\end{array}$ \\
\hline 6. & Saran Lokasi TPSS & $\begin{array}{l}\text { Masyarakat dominan memberikan } \\
\text { saran lokasi yang strategis untuk } \\
\text { penempatan TPSS }\end{array}$ & $\begin{array}{l}\text { Lokasi yang strategis, mudah akses, sistem yang } \\
\text { modern dan tidak mengganggu lalu lintas. }\end{array}$ \\
\hline
\end{tabular}

\subsection{Analisis}

\subsubsection{Sistem Pengelolaan Sampah dan Aturan Peletakkan TPSS}

TPSS yang ada di Denpasar Selatan dikelola oleh pihak DLHK dan ada beberapa lokasi TPSS yang masih dikelola oleh desa seperti Sanur Kauh dan Sanur Kaja namun, untuk pengangkutannya ke TPA tetap dilakukan oleh pihak DLHK. Sistem pengelolaan persampahan di Kecamatan Denpasar Selatan dimulai dari sumber sampah yang terdapat dari permukiman masyarakat kemudian dilanjutkan dengan pengumpulan di rumah masing-masing warga yang disetiap rumah harus disediakan tempat sendiri agar petugas tidak kesusahan dalam pengambilan sampah, dan sampah tersebut tidak boleh diletakkan di area telajakan serta tidak boleh mengganggu fungsi jalan termasuk pedestrian maupun trotar seperti yang tercantum dalam Pasal 3 Bab II Sistem Pengelolaan Sampah Peraturan Walikota Denpasar Nomor 11 Tahun 2016.

Berdasarkan kajian literatur menurut (Mulyansyah, 2008) digunakan sebagai salah satu pertimbangan dalam pemilihan variabel dan kriteria untuk diterapkan dalam penentuan lokasi TPSS di 
Kecamatan Denpasar Selatan, diantaranya yaitu jalan menuju lokasi atau aksesibilitas, jarak TPS terhadap sungai, penggunaan lahan dan ketersediaan lahan.

a. Jalan menuju lokasi

Jalan menuju lokasi merupakan faktor penting untuk penentuan lokasi TPSS, karena setelah dari TPSS truk pengangkut harus segera membawa sampah ke TPA. Jalur yang digunakan untuk TPSS harus dapat diakses oleh truk dan jalur yang digunakan tidak boleh mengganggu aktifitas pengguna jalan utama. Berdasarkan hasil analisis tersebut jarak jalan Nasional dan jalan Provinsi dengan lokasi TPSS yaitu minimal 500 meter dengan tujuan untuk mengantisipasi kemacetan pada jalur tersebut serta agar tidak mengganggu estetika wajah kota (Gambar 3).

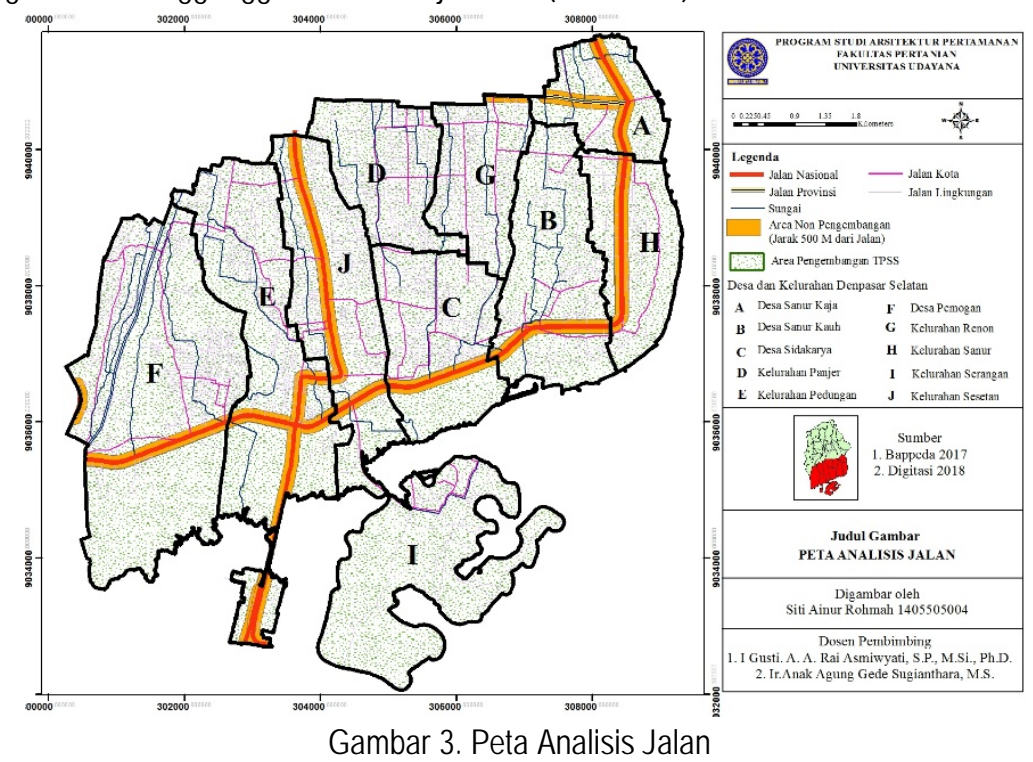

b. Jarak TPSS terhadap sungai

Jarak antara TPSS dan sungai harus diperhatikan untuk mengantisipasi terjadinya pencemaran di area sungai. Penempatan TPSS yang jauh dengan sungai akan jauh lebih baik untuk lingkungan. Berdasarkan hasil penelitian jarak sungai dan TPSS minimal 500 meter untuk mengantisipasi pencemaran terhadap sungai (Gambar 4).

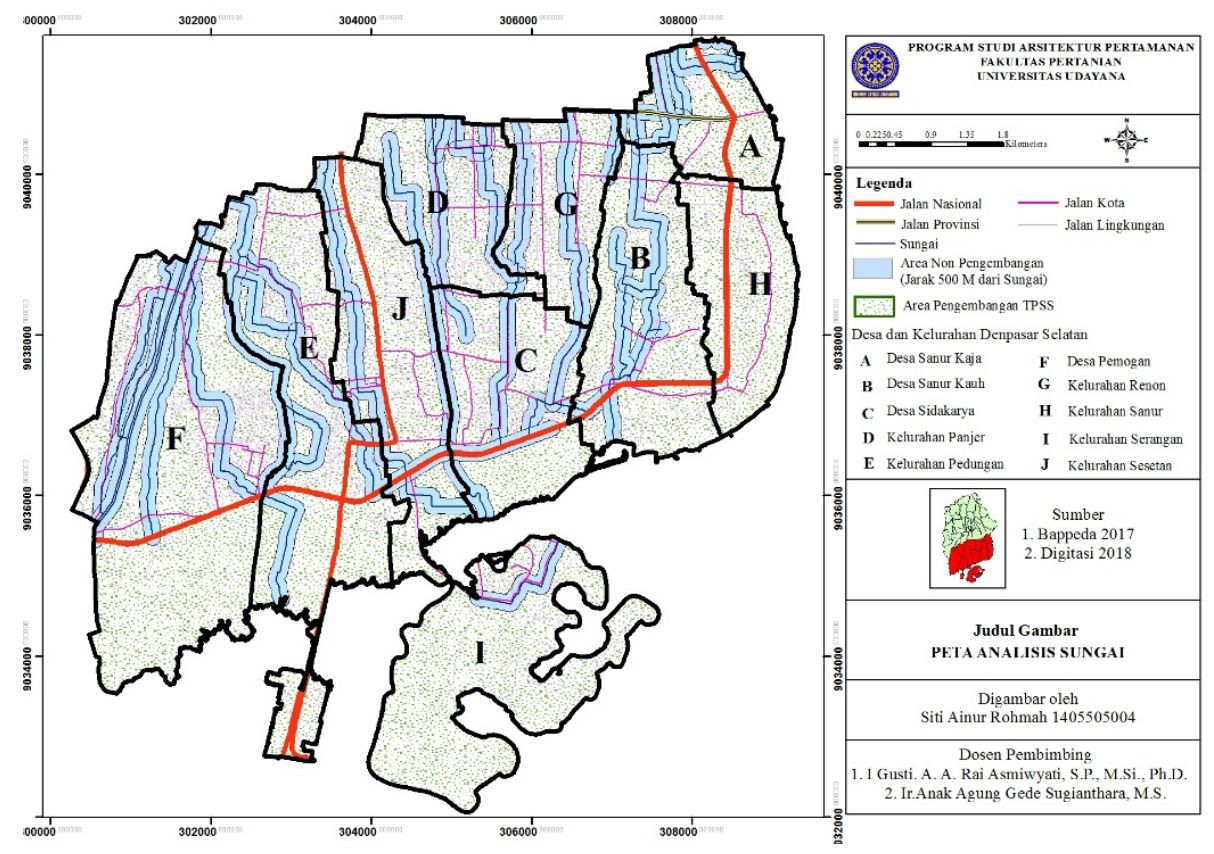

Gambar 4. Peta Analisis Sungai 
c. Penggunaan lahan

Penempatan TPSS pastinya akan membutuhkan lahan, penggunaan lahan yang memenuhi syarat selain mempunyai izin dari pihak pemilik atau pihak desa yang memiliki tanah tersebut. Tanah yang digunakan haruslah tanah yang tidak rusak atau dalam keadaan baik. Penggunaan lahan juga sangat penting memperhatikan lingkungan sekitar seperti pembangunan perumahan, permukiman serta pembangunan TPSS tersebut (Gambar 5)

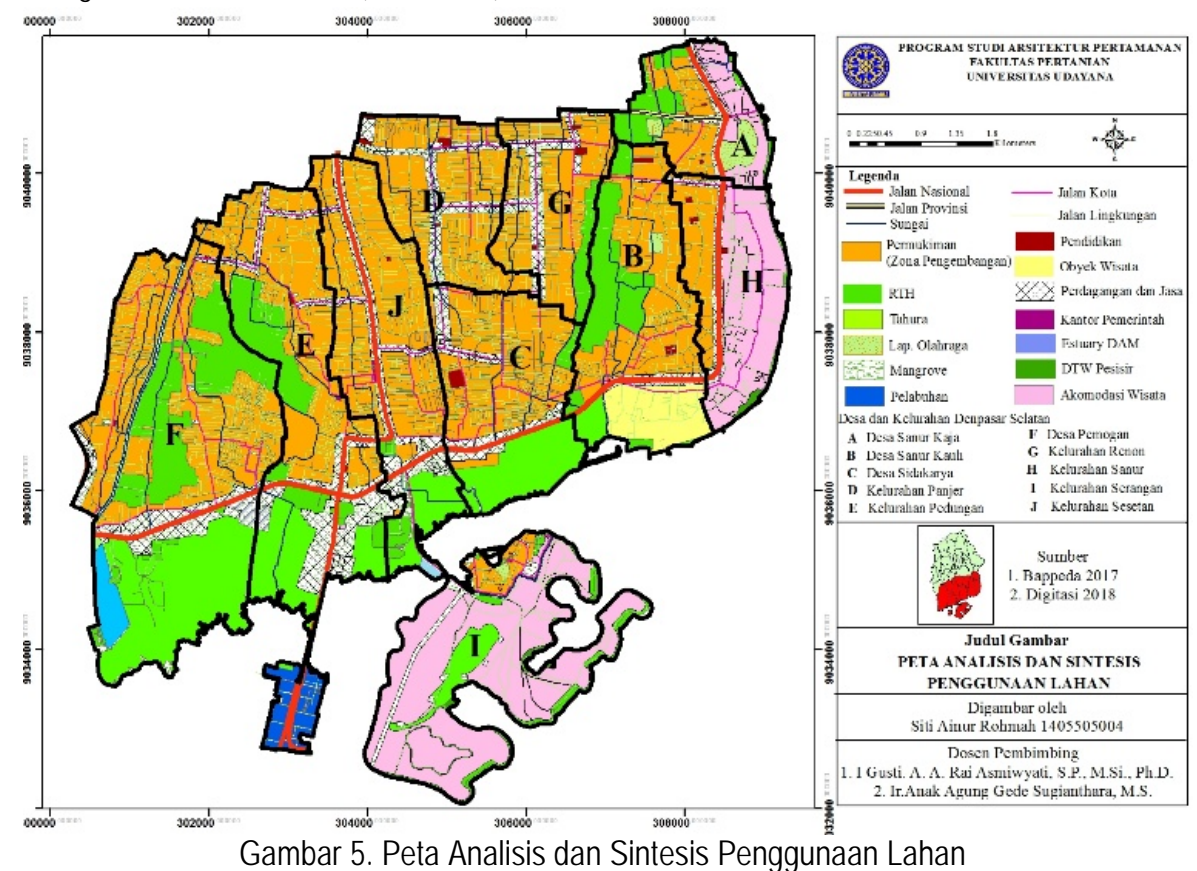

d. Ketersediaan lahan

Ketersediaan lahan memang menjadi persoalan penting untuk lokasi penetuan TPSS, karena harga tanah yang mahal, namun jika pihak pemerintah membutuhkan desa akan membantu (Wiguna, 2018). Berdasarkan dari pihak masyarakat ketika di area permukimaannya diharuskan untuk adanya TPSS banyak dari masyarakat yang menerima dengan syarat TPSS yang digunakan harus menggunakan sistem yang lebih modern, tidak mengganggu lingkungan sekitar seperti pencemaran limbah sampah, tidak menimbulkan bau dan dikelola dengan baik (Gambar 6).

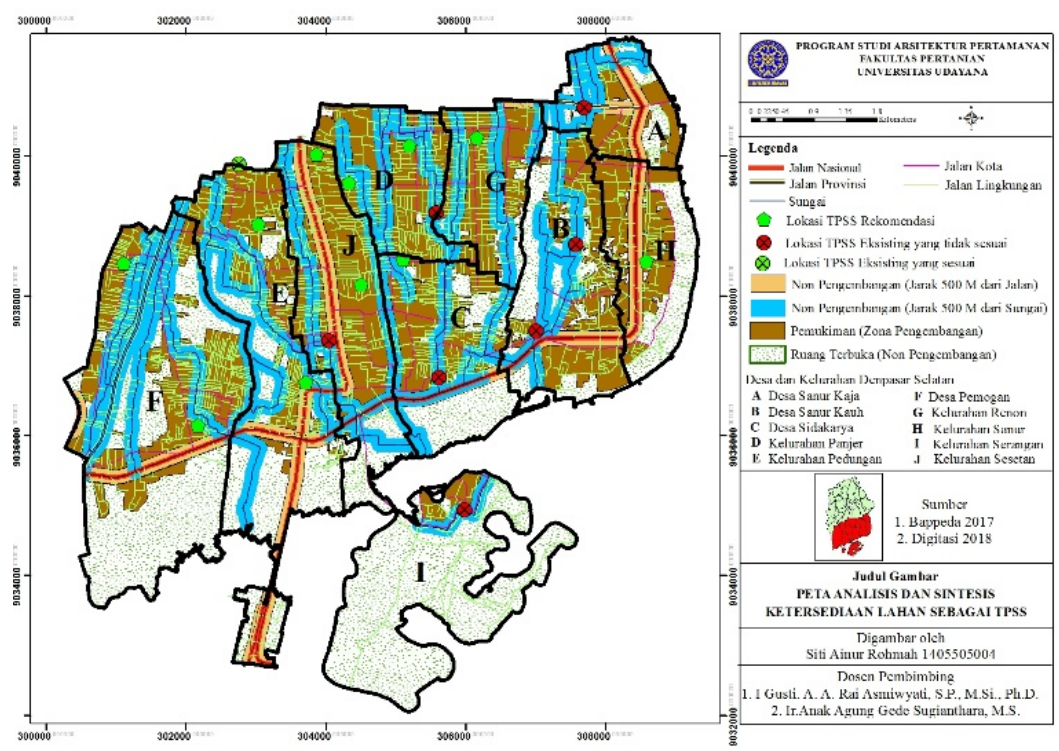

Gambar 6. Peta Analisis dan Sintesis Ketersediaan Lahan sebagai TPSS 


\subsection{Sintesis}

\subsubsection{Sintesis Lokasi TPSS}

Rekomendasi lokasi yang akan dijadikan TPSS merupakan hasil dari observasi lapangan yang dinilai memungkinkan untuk dijadikan TPSS melalui kriteria ketersediaan lahan, jalan menuju lokasi, jaringan jalan, penggunaan tanah dan jarak dengan sungai serta hasil perhitungan dari jumlah penduduk Denpasar Selatan. Jumlah penduduk yang ada di Denpasar Selatan yaitu 286.060 jiwa, dengan jumlah penduduk tersebut dari hasil perhitungan jumlah penduduk setiap wilayah Denpasar Selatan membutuhkan tambahan 11 lokasi TPSS. Lokasi rekomendasi tersebut berada di Kelurahan Sesetan, Desa Pemogan, Kelurahan Pedungan, Desa Sidakarya, Kelurahan Panjer, Kelurahan Sanur, dan Kelurahan Renon (Gambar 7).

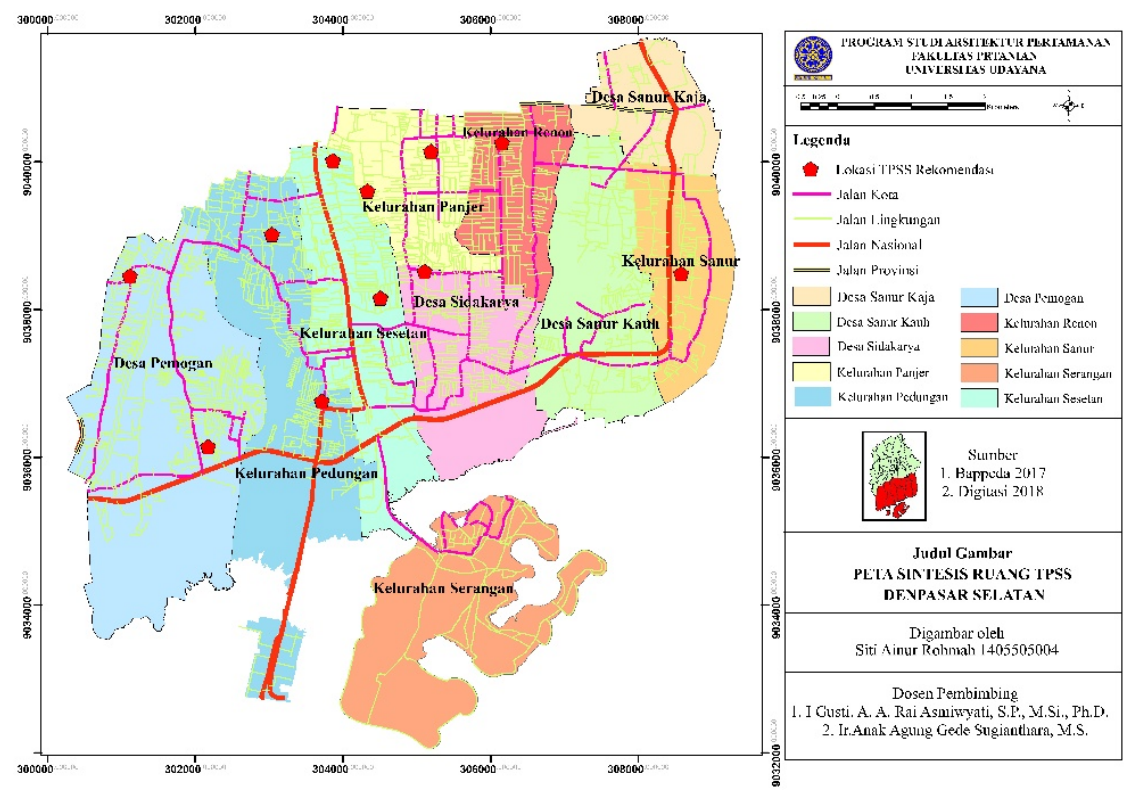

Gambar 7. Peta Sintesis Ruang TPSS Denpasar Selatan

\section{a. Kelurahan Sesetan}

Kelurahan Sesetan memiliki jumlah penduduk sebesar 49.993 jiwa, dengan jumlah penduduk tersebut Kelurahan Sesetan dapat menimbulkan sampah $199.972 \mathrm{~m}^{3}$ setiap harinya. Menurut hasil penelitian Kelurahan Sesetan mempunyai satu lokasi TPSS, namun dengan jumlah sampah tersebut belum dapat menampung sampah yang ada sehingga perlu adanya penampahan jumlah TPSS. Rekomendasi lokasi yang tepat menurut hasil survei dan analisis di Kelurahan Sesetan yaitu di Jalan Mekar Sari dan Jalan Tukad Banyusari.

\section{b. Desa Pemogan}

Desa Pemogan memiliki jumlah penduduk 44.998 jiwa, dengan jumlah penduduk tersebut desa Pemogan menghasilkan 179. $992 \mathrm{~m}^{3}$ sampah setiap harinya. Menurut hasil penelitian desa tersebut tidak memiliki lokasi TPSS, sehingga dari jumlah sampah dan jumlah penduduk tersebut Desa Pemogan membutuhkan dua lokasi TPSS. Peletakkan TPSS menurut hasil survei yaitu di Jalan Gelogor Carik dan di Jalan Sunia Negara.

\section{c. Kelurahan Pedungan}

Kelurahan Pedungan memiliki jumlah penduduk 42.842 jiwa, dengan jumlah penduduk tersebut tersebut dapat menimbulkan 171,368 $\mathrm{m}^{3}$ sampah setiap harinya. Pedungan memiliki satu lokasi TPSS, menurut hasil penelitian TPSS tersebut belum dapat menampung jumlah sampah seluruhnya. Jumlah penduduk tersebut membutuhkan dua TPSS tambahan di Kelurahan Pedungan agar dapat menampung sampah yang ada. Lokasi TPSS yang tepat menurut hasil survei tersebut ada di Jalan Pulau Moyo dan Jalan Pulau Singkep. 


\section{d. Desa Sidakarya}

Jumlah penduduk Desa Sidakarya 27.091 jiwa, dengan jumlah penduduk tersebut Desa Sidakarya dapat menimbulkan sampah 108,364 $\mathrm{m}^{3}$ setiap harinya. Menurut hasil penelitian Desa Sidakarya mempunyai satu lokasi TPSS, namun dengan jumlah sampah tersebut belum dapat menampung sampah yang ada sehingga perlu adanya penampahan jumlah TPSS. Rekomendasi lokasi yang tepat di Desa Sidakarya yaitu di Jalan Tukad Petanu.

\section{e. Kelurahan Panjer}

Kelurahan Panjer memiliki jumlah penduduk 39.523 jiwa, dengan jumlah penduduk tersebut kelurahan Panjer menghasilkan $158.092 \mathrm{~m}^{3}$ sampah setiap harinya. Menurut hasil penelitian Kelurahan Panjer sudah memiliki satu lokasi TPSS, namun dengan jumlah sampah tersebut TPSS yang ada belum dapat menampung semua sampah. Menurut hasil survei seharusnya Kelurahan Panjer menambah dua lokasi TPSS yaitu berada di Jalan Tukad Irawadi dan di Jalan Tukad Batanghari IVB.

\section{f. Kelurahan Sanur}

Sanur memiliki jumlah penduduk 18.345 jiwa, dengan jumlah penduduk tersebut Sanur menghasilkan $73.380 \mathrm{~m}^{3}$ sampah setiap harinya. Berdasarkan hasil penelitian Kelurahan Sanur belum memiliki TPSS, dengan jumlah penduduk tersebut seharusnya Kelurahan Sanur memiliki satu lokasi TPSS. Menurut hasil survei lokasi yang tepat untuk area TPSS di wilayah Sanur yaitu di Jalan Bumi Ayu.

\section{g. Kelurahan Renon}

Kelurahan Renon memiliki jumlah penduduk 20.774 jiwa, dengan jumlah penduduk tersebut Renon dapat menghasilkan $83.096 \mathrm{~m}^{3}$ sampah setiap harinya. Kelurahan Renon belum memiliki TPSS permanen, dengan jumlah penduduk tersebut dan hasil sampah setiap hari seharusnya Renon memiliki satu TPSS. Menurut hasil survei lokasi yang direkomendasikan untuk penempatan TPSS di wilayah Renon yaitu di Jalan Tukad Badung I.

\subsubsection{Pola Jangkauan Ruang TPSS Rekomendasi}

Setelah penentuan lokasi TPSS dilakukan selanjutnya melalukan penentuan pola jangkauan layanan TPSS. Pola jangkauan layanan TPSS ini difungsikan sebagai rekomendasi untuk petugas pelayanan TPSS yang setiap harinya melayani pengambilan sampah kerumah warga. Metode yang digunakan untuk menentukan pola jangkauan wilayah permukiman ke fasilitas pelayan TPSS merupakan pendekatan kualitatif yang dilakukan melalui Sistem Infomasi Geografis yaitu dengan cara melihat antara jangkauan suatu aksesibilitas ke jalan utama terhadap jangkauan lokasi TPSS. Berikut merupakan pola jangkauan fasilitas TPSS (Gambar 8):

1. Wilayah dekat jika masuk dalam wilayah $<2 \mathrm{~km}$ dari fasilitas pelayanan TPSS dan jarak 0-200 meter dari jalan.

2. Wilayah sedang jika masuk dalam wilayah dengan jarak $2-3 \mathrm{~km}$ dari fasilitas pelayanan TPSS dan 201-500 meter dari jalan.

3. Wilayah jauh jika masuk dalam wilayah dengan jarak $>3 \mathrm{~km}$ lebih dari fasilitas pelayanan TPSS dan jarak 501-1000 meter atau lebih dari jalan.

Hasil dari zonasi pola jangkauan rekomendasi yang telah ditentukan menunjukkan sebagian besar wilayah termasuk dalam kategori wilayah dekat yaitu dalam jarak 1-2 km. Jangkauan jalan yang direkomendasikan untuk area yang terlayani petugas pengambil sampah yaitu berjarak sampai $1 \mathrm{~km}$ yang selanjutnya dibawa ke TPSS. Pengembangan alokasi TPSS selanjutnya dapat diprioritaskan dalam wilayah sedang yang berwarna hijau tua dan wilayah jauh berwarna coklat (Gambar 8). Jangkauan wilayah jauh berwarna putih yang terdapat dalam peta (Gambar 8) merupakan area ruang terbuka (seperti sawah atau hutan mangrove) tidak direkomendasikan sebagai lokasi TPSS. 


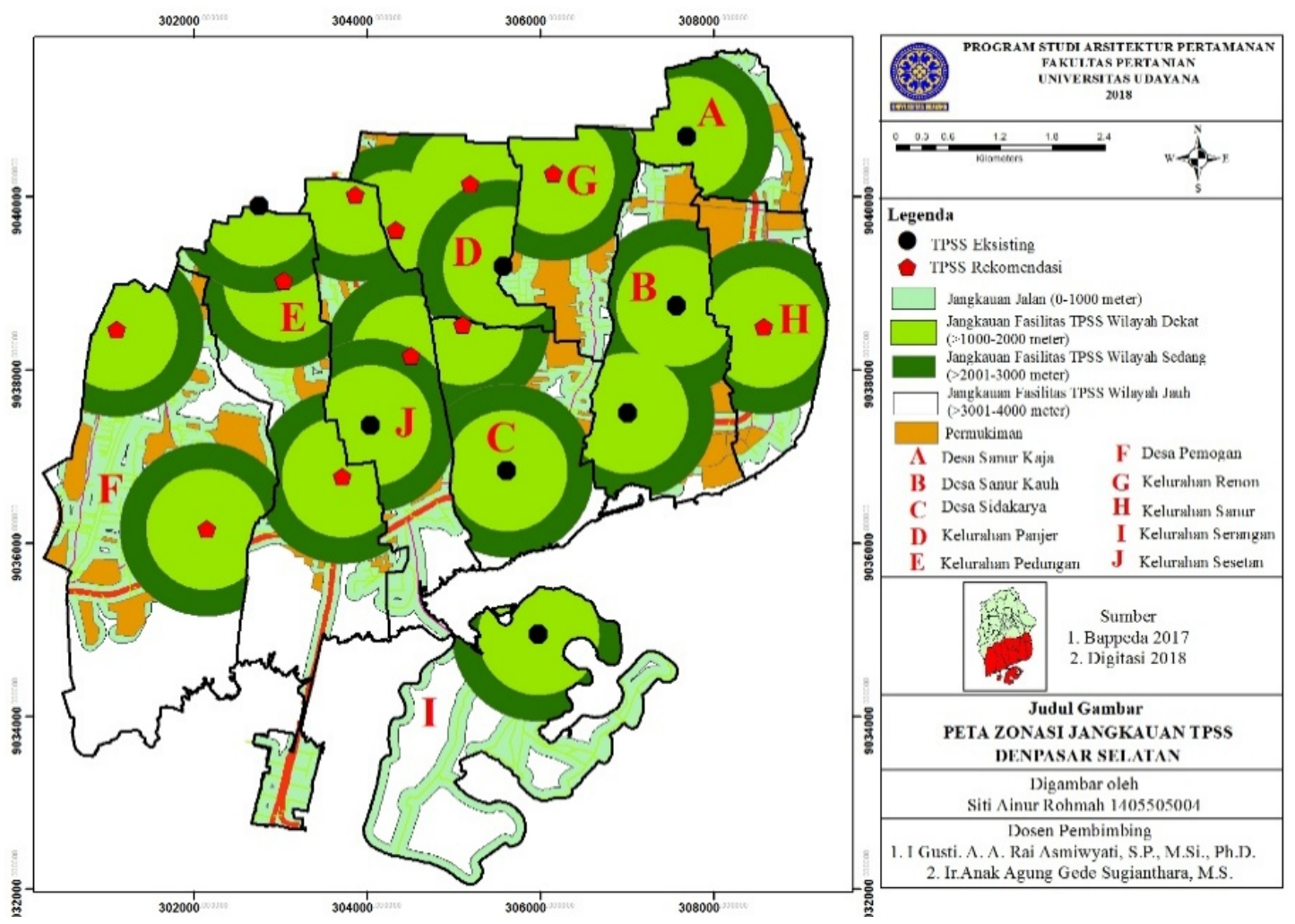

Gambar 8. Peta Zonasi Jangkauan TPSS Denpasar Selatan

\section{Simpulan dan Saran}

4.1 Simpulan

1. TPSS yang berada di Kecamatan Denpasar Selatan berjumlah lima yang dikelola oleh pemerintah dan tiga lokasi yang dikelola sendiri oleh desa. Lokasi TPSS eksisting Denpasar Selatan yaitu di Jalan Pulau Kawe Kelurahan Pedungan, Jalan Citarum di Kelurahan Panjer, Jalan Mertasari di Desa Sidakarya, Jalan Gurita lingkungan Banjar Pegok Kelurahan Sesetan, Jalan Tukad Punggawa Kelurahan Serangan, Jalan Tukad Nyali Sanur Kaja, Gang Zamrud Jalan Batur Sari Sanur Kauh dan Jalan Danau Tempe Sanur Kauh TPS 3R.

2. Dilihat dari kesesuaian lokasi TPSS Eksisting, ada tujuh TPSS yang peletakkannya kurang tepat yaitu TPSS Sidakarya yang berada di pinggir sungai, TPSS Serangan di seberang sungai serta kondisi kurang memadai, TPSS Pegok yang masih dekat dengan sungai dan masih mengganggu fungsi dari lapangan yang letaknya berdekatan, TPSS Sanur Kaja yang letaknya masih dekat dengan sungai, TPSS Palasari Sanur Kauh letaknya yang masih dekat dengan sungai, TPSS 3R Sanur Kauh letaknya yang masih dekat dengan sungai dan TPSS yang masih berkondisi kurang bagus yaitu TPSS yang ada di jalan Citarum Panjer yang masih mengganggu lingkungan masyarakat sekitar dan letaknya masih berdekatan dengan sungai. TPSS yang sudah sesuai yaitu TPSS yang berada di jalan Pulau Kawe.

3. Penambahan lokasi TPSS yang direkomendasikan menyesuaikan dengan jumlah penduduk yang ada dan penentuan lokasinya menggunakan variabel yaitu ketersediaan lahan, jalan menuju lokasi, penggunaan lahan, jarak dengan sungai, serta batas wilayah. Selain itu juga melibatkan persepsi dan preferensi masyarakat Denpasar Selatan sebagai responden melalui kuesioner yang telah disebar. TPSS yang direkomendasikan berjumlah 11 lokasi yang berada di jalan Mekar Sari, di jalan Tukad Banyusari, Jalan Gelogor Carik, Jalan Sunia Negara, Jalan Pulau Moyo, Jalan Pulau Singkep, jalan Tukad Petanu, Jalan Tukad Badung I, Jalan Bumi Ayu, Jalan Tukad Batanghari IVB, dan Jalan Tukad Irawadi. 


\subsection{Saran}

Dari hasil penelitian ini dapat diajukan saran sebagai berikut:

1. Hasil dari penelitian alokasi rekomendasi TPSS ini diharapkan dapat menjadi bahan masukan atau rekomendasi (Pemerintah Kota Denpasar) untuk dimplementasikan. Selain itu TPSS yang sudah ada di Denpasar Selatan agar dikelola dengan baik sesuai dengan aturan yang ada serta dikelola menggunakan alat yang lebih modern agar tidak mencemari lingkungan masyarakat yang tinggal di sekitar TPSS.

2. Perlu adanya papan informasi waktu jadwal pembuangan sampah, agar pembuangan sampah terjadwal saat diangkut ke TPA dan tidak ada sampah sisa di TPSS.

3. Lokasi TPSS sebaiknya jauh dari jangkauan tempat suci atau tempat ibadah.

\section{Daftar Pustaka}

Badan Pusat Statistik (BPS) Kota Denpasar, 2017. Denpasar Selatan Dalam Angka Tahun 2017. Denpasar : Badan Pusat Statistik.

Damanhuri. 2008. Diktat Pengelolaan Sampah. ITB: Bandung

Dinas Lingkungan Hidup Kota Denpasar (DLHK), 2016. Produksi Sampah Setiap Hari Kota Denpasar Tahun 2016. Denpasar : Dinas Lingkungan Hidup.

Kota Denpasar. Peraturan Walikota Denpasar Nomor 11 Tahun 2016 tentang Tata Cara Pengelolaan dan Pembuangan Sampah di Kota Denpasar.

Mulyansyah, A. 2008. Manajemen penentuan lokasi tempat pembuangan sampah sementara berbasis masyarakat di daerah Bekasi. Jurnal Penalaran Mahasiswa FMIPA UI Vol 2 № 3, November 2008. Jurusan Geografi FMIPA UI. Jakarta.

Sekaran, U. 2003. Metodologi Penelitian Untuk Bisnis. Penertbit Salemba 4. Jakarta.

Wiguna, Adi. 2018. Wawancara Pengelolaan TPSS Eksisting Denpasar Selatan. Jl. Majapahit 6. 